\title{
JCTR: Indexing on PubMed
}

\author{
Jennifer L. Hall
}

Published online: 16 June 2010

(C) Springer Science+Business Media, LLC 2010

In 2008, we formed a partnership with Springer to launch a new journal, the Journal of Cardiovascular Translational Research. The rationale was simply recognizing the need for a new direction in publishing that directly addressed translational research. In March 2010, JCTR was accepted for indexing in Pubmed. Twenty to twenty five percent of journals are accepted for indexing in Pubmed (http://www.nlm.nih.gov/pubs/factsheets/ j_sel_faq.html\#a7). JCTR's indexing in Pubmed reflects the acceptance from the community of a need for a Journal dedicated to publishing Translational Research. The Journal continues to gain momentum in thanks to the vision and fortitude of leaders in this field that recognize a role for translational research for our generation and the generations to follow.

A year ago, I stated the editorial team's priority was... "to publish basic insights and discoveries from the research lab and clinic with timely updates on the development of targets through FDA approval." "We

\section{J. L. Hall}

Lillehei Heart Institute, Department of Medicine,

University of Minnesota,

Minneapolis, MN, USA

J. L. Hall

Developmental Biology Center, University of Minnesota,

Minneapolis, MN, USA

J. L. Hall $(\bowtie)$

312 Church Street, 4-106 NHH,

Minneapolis, MN, USA

e-mail: jlhall@umn.edu (also) seek articles that effectively communicate and elucidate the process of development". Our priority has not changed.

Many in the field dissociate, NIH funded translational research with FDA approval. If a survey was taken to determine how many NIH-funded awards in translational research result in a product undergoing the process of FDA approval my guess is this percentage would be low. Why is this? A greater emphasis on discovery and innovation has been placed in the scoring metric for NIH funding. However, the process by which discovery moves to FDA approval has not been adequately addressed. This is a mission for the Journal.

A goal of this Editorial team was to identify critical areas of translational research. We sought input from the FDA, readers of JCTR, and leaders in the field. The FDA suggested devices and stem cells. The readers and leaders in the field identified stem cells and genetics. The International Society of Cardiovascular Translational Research (ISCTR), the society linked to the Journal, is the arm following these critical areas. The third Annual Symposium for ISCTR was held recently in Atlanta GA. Topics included personalized medicine, stem cells, and devices. Speakers on these topics covered innovation, drug discovery, the pathways to FDA approval, and patient care. Dr. Jack Lewin, the current ACC president, spoke at the meeting highlighting the importance of translational research. Shortly thereafter, the ACC and ISCTR formed the beginning of a partnership through which ISCTR would provide a forum at the 2012 ACC meeting to enhance innovation and translational research. Additional workshops will be held throughout the year in focused areas. The dates and locations of these workshops 
are currently being discussed and we hope to bring this information to you in the very near future. Thus, both the Journal and the society are following with articles and action to gain input in critical areas in translational research with the long term goal of policy change.

We look to you for input. Although the Journal was accessible before via Google and Googlescholar, visibility of JCTR now on PubMed will help draw increased readers as well as submitted articles. One more step forward for translational research.

Respectfully,

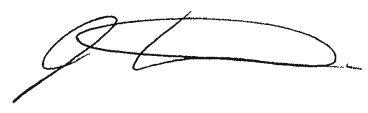

Jennifer L. Hall, FACC, FAHA 